\title{
Mitoxantrone Shows In Vitro, but Not In Vivo Antiviral Activity against Human Respiratory Syncytial Virus
}

\author{
Patricia G. de la Sota (D), Elena Lorente, Laura Notario, Carmen Mir, Oscar Zaragoza and Daniel López * \\ Centro Nacional de Microbiología, Instituto de Salud Carlos III, 28220 Majadahonda, Spain; \\ patric15@ucm.es (P.G.d.1.S.); elorente@isciii.es (E.L.); Inotario@externos.isciii.es (L.N.); \\ carmen.mir@isciii.es (C.M.); ozaragoza@isciii.es (O.Z.) \\ * Correspondence: dlopez@isciii.es; Tel.: +34-9182-23708
}

check for updates

Citation: de la Sota, P.G.; Lorente, E.; Notario, L.; Mir, C.; Zaragoza, O.; López, D. Mitoxantrone Shows In Vitro, but Not In Vivo Antiviral Activity against Human Respiratory Syncytial Virus. Biomedicines 2021, 9 , 1176. https://doi.org/10.3390/ biomedicines 9091176

Academic Editor: Maria Stefania Sinicropi

Received: 10 August 2021

Accepted: 5 September 2021

Published: 7 September 2021

Publisher's Note: MDPI stays neutral with regard to jurisdictional claims in published maps and institutional affiliations.

Copyright: (c) 2021 by the authors. Licensee MDPI, Basel, Switzerland. This article is an open access article distributed under the terms and conditions of the Creative Commons Attribution (CC BY) license (https:// creativecommons.org/licenses/by/ $4.0 /)$.
Abstract: Human respiratory syncytial virus (HRSV) is the most common cause of severe respiratory infections in infants and young children, often leading to hospitalization. In addition, this virus poses a serious health risk in immunocompromised individuals and the elderly. HRSV is also a major nosocomial hazard in healthcare service units for patients of all ages. Therefore, the development of antiviral treatments against HRSV is a global health priority. In this study, mitoxantrone, a synthetic anthraquinone with previously reported in vitro antiprotozoal and antiviral activities, inhibits HRSV replication in vitro, but not in vivo in a mice model. These results have implications for preclinical studies of some drug candidates.

Keywords: antivirals; bioluminescence; drugs; HRSV

\section{Introduction}

Human respiratory syncytial virus (HRSV) [1] is a member of the Pneumoviridae family of the Mononegavirales order. This enveloped Orthopneumovirus is the major cause of severe lower respiratory tract illnesses, such as bronchiolitis and pneumonia, in newborns and young children, with infection rates close to $70 \%$ in the first year of life [2]. At the age of 2-3 years, nearly all children have been infected by HRSV [2], and approximately $2-3 \%$ of infected infants must be hospitalized at higher rates than other respiratory viruses such as human metapneumovirus [3]. As the respiratory damage does not end with the resolution of the infection, some of these children will develop an increased risk for recurrent wheeze and asthma [4]. This virus causes repeated natural infections throughout life in people of all ages [5], although in healthy adults, mild infections are generally the most common clinical outcome, with a mortality risk comparable to that of influenza patients [6]. Generally, yearon-year fluctuations with a shift of dominance between the two viral antigenic subgroups described is produced in both children [7,8] and adults [9]. In addition, severe health risk is also relevant for the immunocompromised [10,11], elderly individuals [12,13], or pregnant women [14]. Worldwide, more than 3.4 million hospital admissions and approximately a quarter of a million deaths each year are associated with HRSV disease, mainly in developing countries $[15,16]$. Moreover, this virus is a major nosocomial hazard in hospital or healthcare service units for patients of all ages [17], involving an important medical as well as economic impact. After nearly 50 years of research, there are still no specific antiviral drugs and no licensed active vaccine against this relevant pathogen. Antiviral treatment development is among the priorities for different organizations such as the WHO and the PATH. In this study, mitoxantrone, a synthetic anthraquinone derivative chemical compound licensed as an anticancer drug [18], but with in vitro antiprotozoal and antiviral activities, was tested in vitro and in vivo as antiviral candidate against HRSV infection. 


\section{Materials and Methods}

\subsection{Mice, Cells, and Viruses}

Rag2-/-BALB/c mice were bred and housed under specific pathogen-free conditions in the animal facilities of the "Instituto de Salud Carlos III" (ISCIII), Majadahonda, Madrid, Spain. All procedures involving animals and their care were approved by the ISCIII Ethics Committees and were conducted according to institutional guidelines. The human epithelial cell line HEp-2 was maintained in DMEM (Gibco BRL, Cheshire, UK) supplemented with $10 \% \mathrm{FBS}$, and cultured at $37{ }^{\circ} \mathrm{C}$ in a $5 \% \mathrm{CO}_{2}$ atmosphere. Two recombinant HRSV viruses were utilized. First, the rrHRSV (kindly supplied by M.E. Peeples) [19]. This is a recombinant HRSV that contains the red fluorescent protein gene inserted as an extra gene immediately downstream of the viral promoter. The red fluorescent protein expression can be detected directly by FACS analyses of infected cells. Second, the rHRSV-Luc [20] with the firefly luciferase $(L u c)$ gene inserted as an extra gene immediately downstream of the matrix gene. Replication of the Luc-encoding virus in living mice can be visualized by bioluminescent imaging [20].

\subsection{In Vitro Infection of HEp-2 Cells and FACS Analysis}

HEp-2 cells were incubated with rrHRSV at an MOI of $1 \mathrm{PFU} /$ cell for $2 \mathrm{~h}$ at $37^{\circ} \mathrm{C}$ to allow virus binding. A mock-infected control culture was included. The cells were further incubated for $24 \mathrm{~h}$ and then harvested for FACS analysis. Cellular DNA topoisomerase I (camptothecin, irinotecan, and topotecan) or II (mitoxantrone, doxorubicin, and etoposide) inhibitors and sulfaguanidine, utilized as negative control, were added 20 min prior to infection. No differences were found in the viability of the infected cells in the absence and presence of the different inhibitors. Data were acquired on a BD Accuri C6 FC flow cytometer (BD Biosciences, San Jose, CA, USA) and analyzed using BDAccuri Samples software (BD Bioscience). The percentage of inhibition is the mean of three independent experiments and was calculated as follows:

$$
100-100 \times\left(\mathrm{MFI}{ }^{\mathrm{HRSV}} \text { with drug }-\mathrm{MFI}{ }^{\text {No HRSV }}\right) /\left(\mathrm{MFI}^{\mathrm{HRSV}}-\mathrm{MFI}^{\text {No HRSV }}\right)
$$

To analyze the statistical significance of the assays, non-parametric Mann-Whitney U test was used. $p$-values $<0.05$ were considered to be statistically significant.

\subsection{Mouse Infections and In Vivo Luminescence Measurements}

In the preclinical study carried out from January 2021 to May 2021, mice were anesthetized by a mixture of ketamine and xylazine ( 1 and $0.2 \mathrm{mg}$ per mouse, respectively) and infected i.n. with $50 \mu \mathrm{L}$ of PBS containing $5 \times 10^{4}$ p.f.u. of rHRSV-Luc. For antiviral drug administration to animals, mitoxantrone was added to the drinking water of mice in order to have $5 \mathrm{mg} / \mathrm{kg}$ in the water consumed by the mice daily. This amount is the maximal tolerated dose previously described for mitoxantrone [21]. New preparations of drinking water were used every two days. Three control mice and three treated with mitoxantrone were anaesthetized and luminescence was measured 5 min after i.n. administration of $50 \mu \mathrm{L}$ of PBS containing $0.75 \mathrm{mg} \mathrm{kg}^{-1}$ D-luciferin (Sigma, St. Louis, MO, USA). Photon emission of rHRSV-Luc-infected mice was measured using the IVIS-Lumina Serie III (Spectrum In Vivo Imaging System) imaging system (Xenogen Corp., Alameda, CA, USA). Living Image software (version 4.4, Caliper Life Sciences, Waltham, MA, USA) was used to measure the luciferase activities. Bioluminescence images were acquired for $1 \mathrm{~min}$ with $\mathrm{f} / \mathrm{stop}=1$ and binning $=8$. A digital false-colour photon emission image of the mouse was generated, and photons were counted within a constant region of interest corresponding to the surface of the chest encompassing the whole-airway area. Photon emission was measured as radiance in $\mathrm{ps}^{-1} \mathrm{~cm}^{-2} \mathrm{sr}^{-1}$, as previously reported [20]. 


\section{Results}

\subsection{In Vitro Anti-HRSV Activity of Mitoxantrone}

The possible antiviral effect of the broad antipathogenic drug mitoxantrone against HRSV infection was carried out. Mitoxantrone, in contrast to the irrelevant drug sulfaguanidine, blocked HRSV replication measured by red protein expression of recombinant HRSV in infected cells (Figure 1). This inhibitory effect was dose-dependent with an $\mathrm{IC}_{50}=4 \mu \mathrm{M}$ (Figure 2). These results showed that mitoxantrone has antiviral activity against not only single-stranded, negative-sense RNA viruses such as HRSV.

\subsection{DNA Topoisomerase I and II Inhibitors Do Not Block the In Vitro HRSV Replication}

Mitoxantrone is a cellular DNA topoisomerase II inhibitor. Therefore, other DNA topoisomerase II inhibitors such as doxorubicin and etoposide were evaluated against HRSV replication. Neither of these two, nor the other three DNA topoisomerase I inhibitors also analyzed, blocked HRSV replication (Figure 3).

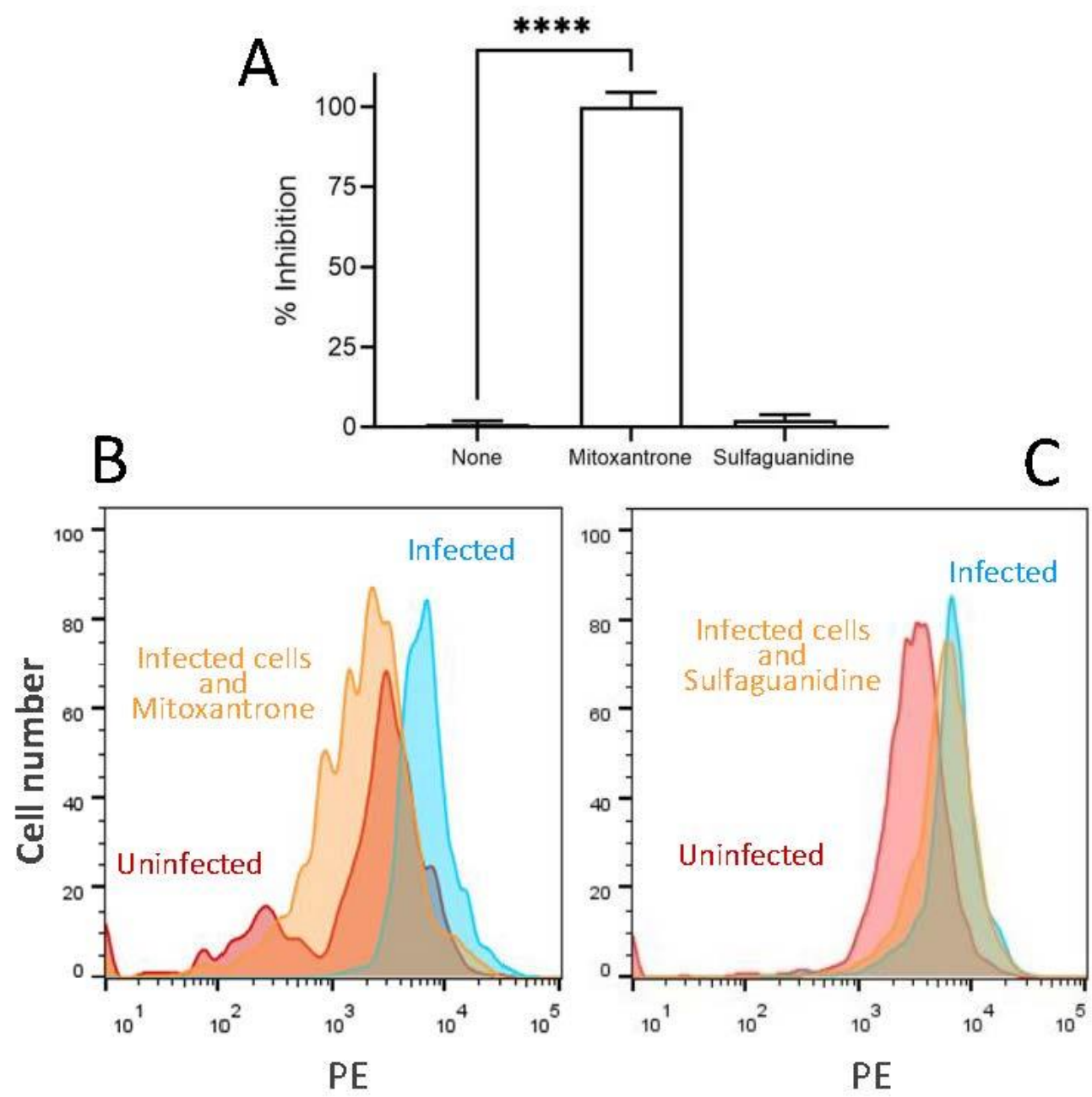

Figure 1. Inhibitory effect of mitoxantrone on HRSV infection of HEP-2 cells. (A) The expression of recombinant red protein in the rrHRSV-infected cells in the presence of different drugs was measured by flow cytometry. The results are calculated as the mean of three independent experiments \pm SD. **** indicated $p$-value $<0.0001$. Representative FACS experiments showing uninfected cells (red) and rrHRSV-infected cells untreated (blue) or treated with mitoxantrone or the irrelevant drug sulfaguanidine at $100 \mu \mathrm{M}$ (yellow) are depicted in panels (B,C), respectively. 


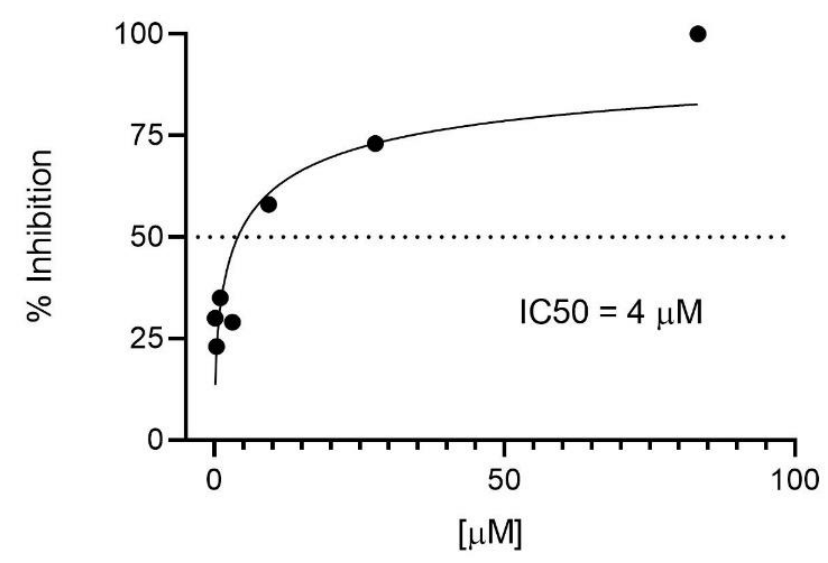

Figure 2. Inhibitory dose-response curve to determine the IC50 for mitoxantrone on HRSV infection of HEP-2 cells. The expression of recombinant red protein in the rrHRSV-infected cells was measured by flow cytometry as Figure 1. The concentration-dependent inhibitory dose-curve data were plotted as percentage of inhibition normalized to uninfected cell controls with applied curve fits calculated using GraphPad Prism.

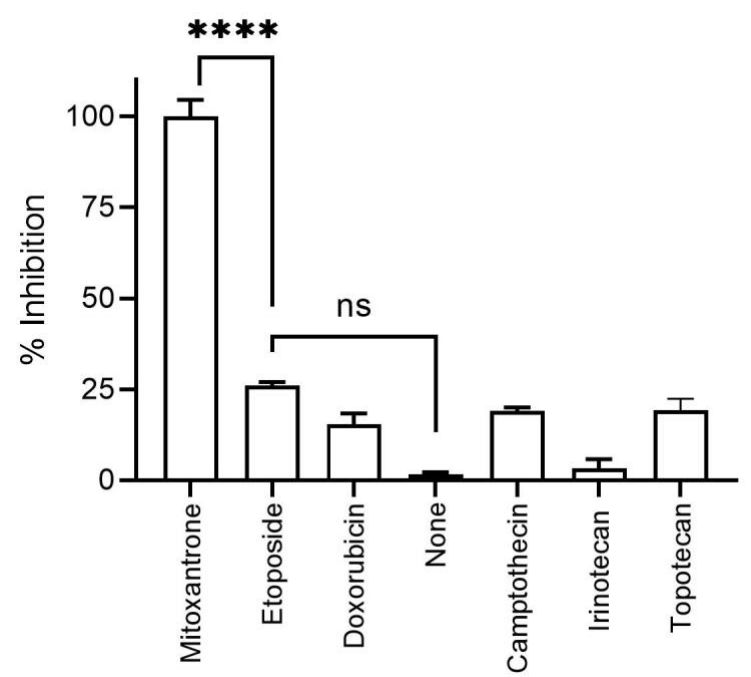

Figure 3. DNA topoisomerase inhibitors on HRSV infection of HEP-2 cells. The expression of recombinant red protein in the rrHRSV-infected cells in the presence of different DNA topoisomerase inhibitors was measured by flow cytometry as Figure 1. Mitoxantrone, doxorubicin, and etoposide are cellular DNA topoisomerase II inhibitors, whereas camptothecin, irinotecan, and topotecan are cellular DNA topoisomerase I inhibitors. The results are calculated as the mean of three independent experiments \pm SD. ${ }^{* * * *}$ indicated $p$-value $<0.0001$.

\subsection{Mitoxantrone Does Not Block the HRSV Replication in Immunodeficient Mice}

The specific and strong effect of mitoxantrone on HRSV replication in cell culture prompted an evaluation of its efficacy in protecting mice against intranasal infection. Rag2 knockout mice present a homozygous disruption of the recombination activating gene 2 . These animals exhibit total inability to initiate $\mathrm{V}(\mathrm{D}) \mathrm{J}$ rearrangement and fail to generate mature $\mathrm{T}$ or B lymphocytes. Thus, in these mice, the adaptive humoral and cellular immune responses are absent and they are unable to eliminate HRSV. Mice infected with rHRSV-Luc received doses of water placebo or water with mitoxantrone starting 5 days after virus infection, and in vivo bioluminescence intensity was determined. As shown in Figure 4, untreated animals developed a persistent infection. Similarly, the bioluminescence was not reduced for mice treated with mitoxantrone (Figure 4). Thus, the treatment with mitoxantrone had no benefit in the intranasal mouse infection model. 


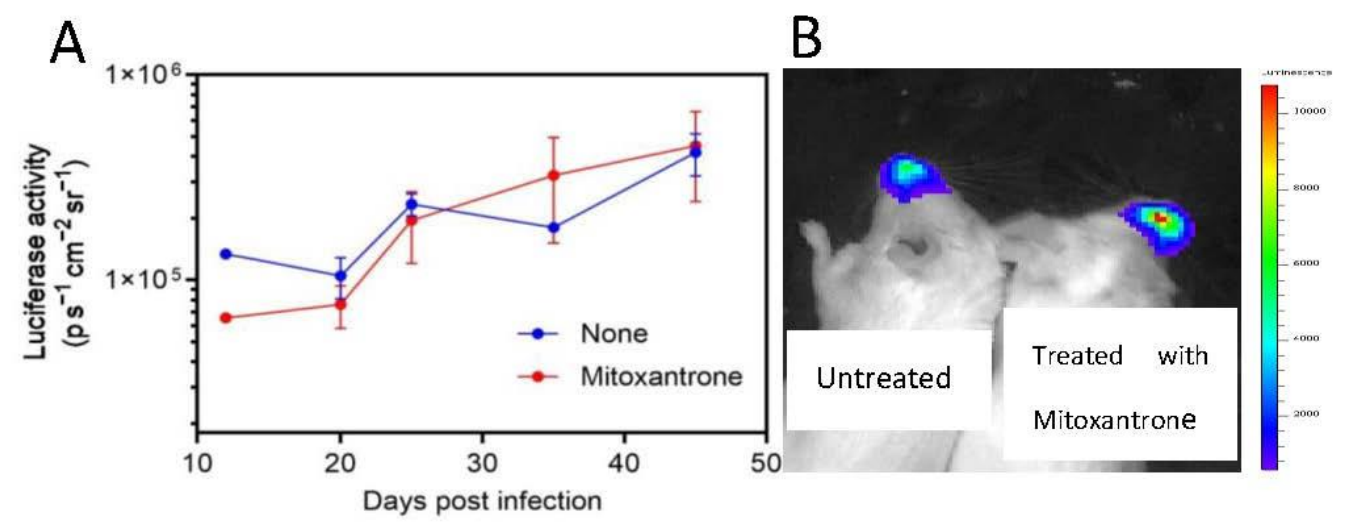

Figure 4. In vivo luminescence of rHRSV-Luc-infected mice treated with mitoxantrone. Panel (A) Six Rag2 mice were infected i.n. at day 0 by rHRSV-Luc. Bioluminescence of untreated (blue) or treated with mitoxantrone (red) mice was measured by capture of photon emission from the nose at different days post infection using the IVIS system. The scale on the left indicates the average radiance: the sum of the photons per second from each pixel inside the region of interest/number of pixels $\left(\mathrm{ps}^{-1} \mathrm{~cm}^{-2} \mathrm{sr}^{-1}\right)$. The results are calculated as the mean of three independent experiments $\pm \mathrm{SD}$. (A) Representative experiment is shown in panel (B).

\section{Discussion}

In the long and expensive road towards identifying new drugs, the "new tricks for old drugs" strategy [22] can bypass the laborious and costly preclinical steps and go straight to clinical trials. This is especially relevant in the development of antivirals or antibiotics, where the interest of the pharmaceutical industry is very limited, and academic scientists can play a relevant role identifying new candidates to inhibitors. In this context, mitoxantrone, an anthracenedione with antineoplastic activity utilized mainly in acute lymphoblastic leukemia [23], breast cancer [24], and prostate cancer [25], is an interesting drug as it has previously been described as an antiprotozoal and antiviral agent. Mitoxantrone was described initially as a cellular DNA topoisomerase II inhibitor, which causes singleand double-stranded disruptions and DNA repair suppression by its intercalation between DNA bases. This mechanism of action would explain their antineoplastic and antiprotozoal activities. However, mitoxantrone also has in vitro antiviral activity against human herpes simplex virus by suppression of the viral immediate early genes, which are transcribed by cellular RNA polymerase II in a highly regulated cascade [26], although the direct interaction between this enzyme and the drug has not been described to date. In addition, mitoxantrone inhibits in vitro, but not in vivo vaccinia virus replication by blocking virion assembly, but not protein synthesis, by an unknown mechanism of action [21]. Recently, in vitro inhibition of SARS-CoV-2 has been described involving cell surface heparan sulfate as cofactor [27]. These pleiotropic effects, involving both different species and mechanisms of action, would suggest additional targets of this drug. Thus, in the current study, we tested the activity of mitoxantrone against HRSV replication. Our data showed that mitoxantrone (but not other cellular DNA topoisomerase I and II inhibitors) also prevents in vitro replication of HRSV. This fact is very interesting because HRSV is a single-stranded, negative-sense RNA virus, unrelated phylogenetically to poxviruses or herpesviruses, both double-stranded DNA pathogens that possesses large genomes or positive-sense single-stranded RNA coronaviruses. Thus, our data suggest that an additional mechanism of action to previously characterized or still unknown is involved in the anti-HRSV activity of mitoxantrone. In addition, all these data open the possibility that this drug may have additional antiviral properties against other viruses to those described by us and the other groups who have worked previously with mitoxantrone. This is a hypothesis that should be analyzed in depth in future studies.

In the next step of the "new tricks for old drugs" strategy, we analyzed the effect of mitoxantrone in an immunodeficient mouse model, which eliminates the contribution 
of the immune system to viral clearance, thus the real effect of the antiviral treatment is discovered. Unfortunately, as in many other drug candidates in multiple preclinical studies, mitoxantrone failed to control HRSV infection in the in vivo experiments. However, drug efficacy testing in mice has several limitations. First, the time of divergence between humans and rodents is estimated to be approximately 96 million years ago [28]. This implies that absorption, distribution, metabolism, excretion, effectiveness, and toxicity of drugs can be very different in organisms so phylogenetically distant. For example, corticosteroids are extensively teratogenic in animals, but not in humans [29], and thalidomide is not a teratogen in many animal species, but it is in humans [30]. In addition, humans and mice have different genes, regulatory regions, or even evolutionary paths. However, even though humans and mice share the same genes, and these are sufficiently conserved, the homolog genes can be used in different ways in each specie. Thus, as "mice are not simply furry little people", animal studies are often poor predictors of human reactions. In this context, a chemical compound such as mitoxantrone with such broad antiprotozoal and antiviral activities could be directly analyzed in humans despite the failure of in vivo animal testing against HRSV and vaccinia virus [21].

Author Contributions: Conceptualization, D.L.; methodology, D.L.; formal analysis, P.G.d.l.S. and D.L.; investigation, P.G.d.I.S., E.L., L.N., and C.M.; Resources, O.Z.; writing—original draft preparation, D.L.; writing—review and editing, D.L.; supervision, D.L.; funding acquisition, D.L. All authors have read and agreed to the published version of the manuscript.

Funding: This work was supported by the Spanish Ministry of Science and Innovation SAF201458052 and "Acción Estratégica en Salud" MPY 388/18 to D.L.

Institutional Review Board Statement: The study was conducted according to the guidelines of the Declaration of Helsinki, and approved by the Institutional Review Board of the Instituto de Salud "Carlos III" (protocol code 28079-34A, September 2019).

Informed Consent Statement: Not applicable.

Data Availability Statement: The data presented in this study are available on request from the corresponding author.

Acknowledgments: Mark E. Peeples (Department of Immunology /Microbiology, Rush-PresbyterianSt. Luke's Medical Center, Chicago, IL, USA) kindly provided the rrHRSV. Jean-François Eléouët (Unité de Virologie et Immunologie Moleculaires, INRA, Jouy-en-Josas, France) kindly provided the rHRSV-Luc.

Conflicts of Interest: The authors declare no conflict of interest. The funders had no role in the design of the study; in the collection, analyses, or interpretation of data; in the writing of the manuscript; or in the decision to publish the results.

\section{References}

1. Collins, P.L.; Chanock, R.M.; Murphy, B.R. Respiratory Syncytial Virus. In Fields Virology; Knipe, D.M., Howley, P.M., Eds.; Lippincott Williams \& Wilkins: Philadelphia, PA, USA, 2013; pp. 1086-1124.

2. Glezen, P.; Denny, F.W. Epidemiology of acute lower respiratory disease in children. N. Engl. J. Med. 1973, 288, 498-505. [CrossRef] [PubMed]

3. Taniguchi, A.; Kawada, J.I.; Go, K.; Fujishiro, N.; Hosokawa, Y.; Maki, Y.; Sugiyama, Y.; Suzuki, M.; Tsuji, T.; Hoshino, S.; et al. Comparison of Clinical Characteristics of Human Metapneumovirus and Respiratory Syncytial Virus Infections in Hospitalized Young Children. Jpn. J. Infect. Dis. 2019, 72, 237-242. [CrossRef]

4. Simoes, E.A.; Carbonell-Estrany, X.; Rieger, C.H.; Mitchell, I.; Fredrick, L.; Groothuis, J.R. The effect of respiratory syncytial virus on subsequent recurrent wheezing in atopic and nonatopic children. J. Allergy Clin. Immunol. 2010, 126, 256-262. [CrossRef] [PubMed]

5. Henderson, F.W.; Collier, A.M.; Clyde, W.A., Jr.; Denny, F.W. Respiratory-syncytial-virus infections, reinfections and immunity. A prospective, longitudinal study in young children. N. Engl. J. Med. 1979, 300, 530-534. [CrossRef] [PubMed]

6. Chen, L.; Han, X.; Bai, L.; Zhang, J. Clinical characteristics and outcomes in adult patients hospitalized with influenza, respiratory syncytial virus and human metapneumovirus infections. Expert. Rev. Anti. Infect. Ther. 2021, 19, 787-796. [CrossRef] [PubMed] 
7. Korsun, N.; Angelova, S.; Tzotcheva, I.; Georgieva, I.; Lazova, S.; Parina, S.; Alexiev, I.; Perenovska, P. Prevalence and genetic characterisation of respiratory syncytial viruses circulating in Bulgaria during the 2014/15 and 2015/16 winter seasons. Pathog. Glob. Health 2017, 111, 351-361. [CrossRef]

8. Korsun, N.; Angelova, S.; Trifonova, I.; Voleva, S.; Grigorova, I.; Tzotcheva, I.; Mileva, S.; Alexiev, I.; Perenovska, P. Predominance of ON1 and BA9 genotypes of respiratory syncytial virus (RSV) in Bulgaria, 2016-2018. J. Med. Virol. 2021, 93, $3401-3411$. [CrossRef]

9. Xiang, Z.; Gonzalez, R.; Ren, L.; Xiao, Y.; Chen, L.; Zhang, J.; Wang, W.; Yang, Q.; Li, J.; Zhou, H.; et al. Prevalence and clinical characteristics of human respiratory syncytial virus in Chinese adults with acute respiratory tract infection. J. Med. Virol. 2013, 85, 348-353. [CrossRef]

10. Wendt, C.H.; Hertz, M.I. Respiratory syncytial virus and parainfluenza virus infections in the immunocompromised host. Semin. Respir. Infect. 1995, 10, 224-231.

11. Ison, M.G.; Hayden, F.G. Viral infections in immunocompromised patients: What's new with respiratory viruses? Curr. Opin. Infect. Dis. 2002, 15, 355-367. [CrossRef]

12. Han, L.L.; Alexander, J.P.; Anderson, L.J. Respiratory syncytial virus pneumonia among the elderly: An assessment of disease burden. J Infect. Dis 1999, 179, 25-30. [CrossRef]

13. Falsey, A.R.; Hennessey, P.A.; Formica, M.A.; Cox, C.; Walsh, E.E. Respiratory syncytial virus infection in elderly and high-risk adults. N. Engl. J. Med. 2005, 352, 1749-1759. [CrossRef] [PubMed]

14. Hause, A.M.; Avadhanula, V.; Maccato, M.L.; Pinell, P.M.; Bond, N.; Santarcangelo, P.; Ferlic-Stark, L.; Ye, X.; Iwuchukwu, O.; Maurer, L.; et al. Clinical characteristics and outcomes of respiratory syncytial virus infection in pregnant women. Vaccine 2019, 37, 3464-3471. [CrossRef] [PubMed]

15. Nair, H.; Nokes, D.J.; Gessner, B.D.; Dherani, M.; Madhi, S.A.; Singleton, R.J.; O’Brien, K.L.; Roca, A.; Wright, P.F.; Bruce, N.; et al. Global burden of acute lower respiratory infections due to respiratory syncytial virus in young children: A systematic review and meta-analysis. Lancet 2010, 375, 1545-1555. [CrossRef]

16. Lozano, R.; Naghavi, M.; Foreman, K.; Lim, S.; Shibuya, K.; Aboyans, V.; Abraham, J.; Adair, T.; Aggarwal, R.; Ahn, S.Y.; et al. Global and regional mortality from 235 causes of death for 20 age groups in 1990 and 2010: A systematic analysis for the Global Burden of Disease Study 2010. Lancet 2012, 380, 2095-2128. [CrossRef]

17. Hall, C.B. Nosocomial respiratory syncytial virus infections: The "Cold War" has not ended. Clin. Infect. Dis. 2000, 31, 590-596. [CrossRef] [PubMed]

18. Tikhomirov, A.S.; Shtil, A.A.; Shchekotikhin, A.E. Advances in the Discovery of Anthraquinone-Based Anticancer Agents. Recent Pat. Anticancer Drug Discov. 2018, 13, 159-183. [CrossRef]

19. Guerrero-Plata, A.; Casola, A.; Suarez, G.; Yu, X.; Spetch, L.; Peeples, M.E.; Garofalo, R.P. Differential response of dendritic cells to human metapneumovirus and respiratory syncytial virus. Am. J. Respir. Cell Mol. Biol. 2006, 34, 320-329. [CrossRef]

20. Rameix-Welti, M.A.; Le, G.R.; Herve, P.L.; Sourimant, J.; Remot, A.; Riffault, S.; Yu, Q.; Galloux, M.; Gault, E.; Eleouet, J.F. Visualizing the replication of respiratory syncytial virus in cells and in living mice. Nat. Commun. 2014, 5, 5104. [CrossRef] [PubMed]

21. Deng, L.; Dai, P.; Ciro, A.; Smee, D.F.; Djaballah, H.; Shuman, S. Identification of novel antipoxviral agents: Mitoxantrone inhibits vaccinia virus replication by blocking virion assembly. J. Virol. 2007, 81, 13392-13402. [CrossRef] [PubMed]

22. O'Connor, K.A.; Roth, B.L. Finding new tricks for old drugs: An efficient route for public-sector drug discovery. Nat. Rev. Drug Discov. 2005, 4, 1005-1014. [CrossRef] [PubMed]

23. Chen KT, J.; Gilabert-Oriol, R.; Bally, M.B.; Leung AW, Y. Recent Treatment Advances and the Role of Nanotechnology, Combination Products, and Immunotherapy in Changing the Therapeutic Landscape of Acute Myeloid Leukemia. Pharm. Res. 2019 , $36,125$. [CrossRef] [PubMed]

24. Shah, N.; Mohammad, A.S.; Saralkar, P.; Sprowls, S.A.; Vickers, S.D.; John, D.; Tallman, R.M.; Lucke-Wold, B.P.; Jarrell, K.E.; Pinti, M.; et al. Investigational chemotherapy and novel pharmacokinetic mechanisms for the treatment of breast cancer brain metastases. Pharmacol. Res. 2018, 132, 47-68. [CrossRef]

25. Reichert, Z.R.; Hussain, M. Androgen Receptor and Beyond, Targeting Androgen Signaling in Castration-Resistant Prostate Cancer. Cancer J. 2016, 22, 326-329. [CrossRef]

26. Huang, Q.; Hou, J.; Yang, P.; Yan, J.; Yu, X.; Zhuo, Y.; He, S.; Xu, F. Antiviral activity of mitoxantrone dihydrochloride against human herpes simplex virus mediated by suppression of the viral immediate early genes. BMC. Microbiol. 2019, 19, 274. [CrossRef]

27. Zhang, Q.; Chen, C.Z.; Swaroop, M.; Xu, M.; Wang, L.; Lee, J.; Wang, A.Q.; Pradhan, M.; Hagen, N.; Chen, L.; et al. Heparan sulfate assists SARS-CoV-2 in cell entry and can be targeted by approved drugs in vitro. Cell Discov. 2020, 6, 80. [CrossRef] [PubMed]

28. Nei, M.; Xu, P.; Glazko, G. Estimation of divergence times from multiprotein sequences for a few mammalian species and several distantly related organisms. Proc. Natl. Acad. Sci. USA 2001, 98, 2497-2502. [CrossRef] [PubMed]

29. Needs, C.J.; Brooks, P.M. Antirheumatic medication in pregnancy. Br. J. Rheumatol. 1985, 24, 282-290. [CrossRef] [PubMed]

30. Lepper, E.R.; Smith, N.F.; Cox, M.C.; Scripture, C.D.; Figg, W.D. Thalidomide metabolism and hydrolysis: Mechanisms and implications. Curr. Drug Metab. 2006, 7, 677-685. [CrossRef] [PubMed] 